\title{
An unexpected disruption of the atmospheric Quasi-Biennial Oscillation
}

\author{
Authors: Scott M. Osprey ${ }^{1 *}$, Neal Butchart ${ }^{2}$, Jeff R. Knight ${ }^{2}$, Adam A. Scaife ${ }^{2,6}$, Kevin \\ Hamilton $^{3}$, James A. Anstey ${ }^{4}$, Verena Schenzinger ${ }^{1}$, Chunxi Zhang ${ }^{3}$
}

\author{
Affiliations: \\ ${ }^{1}$ NCAS-Climate, University of Oxford, Atmospheric, Oceanic \& Planetary Physics, Clarendon \\ Laboratory, Parks Road, Oxford, OX1 3PU, United Kingdom. \\ ${ }^{2}$ Met Office Hadley Centre, FitzRoy Road, Exeter, Devon, EX1 3PB, United Kingdom. \\ ${ }^{3}$ International Pacific Research Center, University of Hawai i, Honolulu, USA. \\ ${ }^{4}$ Canadian Centre for Climate Modelling and Analysis, University of Victoria, Victoria, British \\ Columbia, Canada. \\ ${ }^{6}$ Department of Mathematics and Computer Science, University of Exeter, Exeter, UK. \\ *Correspondence to: Scott.Osprey@physics.ox.ac.uk.
}

\begin{abstract}
One of the most repeatable phenomena seen in the atmosphere, the quasi-biennial oscillation (QBO) between prevailing eastward and westward wind-jets in the equatorial stratosphere ( 16-50 km altitude), was unexpectedly disrupted in February 2016. An unprecedented westward jet formed within the eastward phase in the lower stratosphere and cannot be accounted for by the standard QBO paradigm based on vertical momentum transport. Instead the primary cause was waves transporting momentum from the Northern Hemisphere. Seasonal forecasts did not predict the disruption but analogous QBO disruptions are seen very occasionally in some climate simulations. A return to more typical QBO behavior within the next year is forecast, though the possibility of more frequent occurrences of similar disruptions is projected for a warming climate.
\end{abstract}

One Sentence Summary: In 2016 the usual quasi-periodic equatorial oscillation in the stratosphere between eastward and westward winds unexpectedly breaks down around $25 \mathrm{~km}$ altitude.

\section{Main Text:}

Aside from those variations governed by the changing seasons or diurnal cycle, the quasibiennial oscillation (QBO) is arguably the most repeatable mode of natural variability seen anywhere in the atmosphere. It was first discovered in the late $1950 \mathrm{~s}(1,2)$ and features alternating eastward and westward wind-jets descending through the equatorial stratosphere, at roughly $1 \mathrm{~km}$ per month (3), from $\sim 50 \mathrm{~km}(\sim 1 \mathrm{hPa})$ down to $\sim 16 \mathrm{~km}(\sim 100 \mathrm{hPa})$, with the quasibiennial periodicity being most evident in the $\sim 20-40 \mathrm{~km}$ layer. Since the 1950 s the period of the oscillation has varied between 22 to 36 months. The oscillation is nearly zonally uniform and so is seen in both local observations and in longitudinally averaged data with roughly the same amplitude, at least for monthly means, and is confined to equatorial latitudes $(4,5)$. On the other hand its influence is felt throughout the atmosphere. For example, the fate of ash and sulfur from large volcanic eruptions in the tropics is affected by the QBO (6) and there are known surface weather and climate impacts resulting from the QBO's extra-tropical teleconnections (7-9); such 
teleconnections may provide an important source of predictability that can be exploited by seasonal and decadal prediction systems (10), due to the regularity of the QBO. Disruption to the regular QBO behavior is therefore expected to have potentially far-reaching consequences.

In November 2015 the QBO winds were westward above $30 \mathrm{~km}(\sim 15 \mathrm{hPa})$ and eastward beneath. During November and December 2015 the westward phase propagated downward as is typical (Fig. 1A), but by January 2016 its descent had stalled. While by itself this was not unusual (e.g., Fig. 1A, during early 2009, just above $20 \mathrm{hPa}$ ), the stalling was followed by the unexpected formation of a second westward layer interrupting the lower stratospheric eastward phase (near $40 \mathrm{hPa}$ ). Subsequently, the descending westward phase in the upper stratosphere began to recede, while the anomalous westward jet below strengthened and began to descend. Here we quantify the extent to which this behavior is anomalous compared to the previous six decades of observations containing 27 QBO cycles.

The state of the QBO is often characterized using an updated time series of monthly-mean balloon observations of near-equatorial zonal winds (11). This record spans essentially the entire era of operational tropical stratospheric wind soundings from January 1956 to present day and provides 724 monthly profiles of the equatorial zonal wind. For each of these profiles we identified a "best match" month having the smallest root mean square (rms) difference over 7 levels spanning $70-10 \mathrm{hPa}$ (Fig. 1B). For the vast majority of months there is a close match with another month in the record and rms differences are typically $2-3 \mathrm{~ms}^{-1}$. Before 2016 the month with the largest rms difference with its best historical match was December1988 $\left(4.8 \mathrm{~ms}^{-1}\right)$. The unprecedented behavior in 2016 is apparent as February, March, and April 2016 have rms differences of $6.7,10.1$ and $6.8 . \mathrm{ms}^{-1}$, respectively.

Canonical theory describes the QBO as driven by the interaction of the zonal mean flow with a spectrum of vertically-propagating waves forced in the lower atmosphere and dissipated within the stratosphere $(12,13)$. Mean-flow driving is proportional to local vertical wind shear such that where there is westward vertical shear the mean flow is accelerated westward and vice versa for eastward vertical shear. This leads to the downward phase propagation of the alternating QBO wind regimes seen throughout the observed record (e.g., Fig. 1A). The selective filtering of upward propagating waves by low level jets then leads to opposite sign acceleration at higher levels in a "shadowing effect". Climatological large scale upwelling in the equatorial stratosphere (14) opposes the downward phase propagation (15) and can contribute to the descent stalling, while the forcing of the westward phase can be supplemented by horizontally propagating quasi-stationary planetary waves from the extratropics, particularly in boreal winter $(16-19)$.

As the strong westward accelerations near $30-50 \mathrm{hPa}$ in late 2015 and early 2016 occur in a region of eastward mean flow shear they cannot be accounted for by the canonical theory of the underlying winds. On the other hand, fluxes of wave-activity (Fig. 2A, arrows) averaged for February 2016 suggest that waves propagating from the Northern Hemisphere might be the most likely cause of the westward acceleration (planetary scale Rossby waves propagating from the extra-tropics can only transport westward momentum). Typically during winter months upward wave activity fluxes enter the stratosphere at mid to high latitudes then refract equatorward. In February 2016 the anomalously strong high latitude eastward jet was unusually flanked by subtropical westward winds above $\sim 30 \mathrm{hPa}$ (Fig. 2A). As these westward winds do not favour Rossby wave propagation (21) the wave flux is confined to the region below, turning horizontal and equatorward (Fig. 2A). The QBO so happened to be in its eastward phase at this level which 
allows the waves to propagate all the way to the equator near $40 \mathrm{hPa}$. Summertime westward winds prevent further propagation across the equator into the Southern Hemisphere. The resultant wave dissipation causes a westward acceleration at the equator.

Confirmation of the above analysis is provided by the monthly mean momentum budget at 40 $\mathrm{hPa}$ for late 2015 and early 2016 (Fig. 2B). Dominating the westward acceleration of the equatorial winds at this level up to February 2016 is the contribution from the horizontally propagating waves. This contribution declines once the winds at this level become westward (negative) in February, leaving a balance between the driving from the vertically propagating waves and the opposing upwelling and a return to the standard QBO paradigm. As this westward jet develops near $40 \mathrm{hPa}$, eastward acceleration appears near $20-30 \mathrm{hPa}$ in the familiar "shadowing" pattern predicted by the canonical theory.

The QBO's long period and great regularity make it the most predictable long term atmospheric variation after the annual cycle. Tests over many past cycles of the QBO confirm that this normally allows skilful predictions out to a few years ahead (10), yet the recent disruption of the oscillation shows very different characteristics. A seasonal climate prediction made in December 2015 and initialised with the atmospheric and oceanic state at the time (20) showed over the subsequent months a clear continuation and descent of the eastward phase of the QBO into the lower stratosphere with no sign of the spontaneous appearance of westward flow in the lower stratosphere as occurred in observations (Fig. 3A). This is in sharp contrast to the usual skilful predictions of the QBO out to years ahead (10) and the recent disruption of the QBO cycle was therefore not predicted, even just one month in advance.

This low predictability is consistent with the origin of the QBO's disruption being found in the extratropical atmosphere, where variability is inherently less predictable. The occurrence of a disruption to the eastward phase of the oscillation is also consistent with an extratropical origin from the winter hemisphere, because transient Rossby waves occurring in the winter stratosphere can only propagate into eastward flow, and deliver westward acceleration to the mean flow. Furthermore the stronger tropical upwelling during Boreal winter slows down the QBO's descent allowing more time for the extratropical waves to impact during this particular phase.

Of course it is also possible that our current numerical models can not properly represent the processes disrupting the QBO. To investigate this, the foregoing rms analysis that was applied to the observational record was applied to historical global climate model runs to identify possible analogous events (Fig. 4A-C). Among the available models that produce a QBO internally, only one rarely produced behavior similar to the observed disruption, with an example shown in Fig. 4D. The extreme profiles resemble those observed during 2016 with a thin layer of westward wind appearing within an otherwise eastward QBO phase.

What will happen next? The recent disruption of the QBO is a rare event that occurs in the northern winter. The forecast initialised after the disruption (Fig. 3B) suggests that the QBO will return to more regular phase progression over the coming year. The westward jet that suddenly appeared in the lower stratosphere is predicted to amplify in the summer of 2016 and progress downward with time. Eastward flow then descends from the $20 \mathrm{hPa}$ level and dominates the lower stratospheric flow towards the end of 2016, returning the QBO to its typical behavior. We then expect regular and predictable QBO cycling to continue from 2017, as occurs in the available climate models (e.g. Fig 4D). Nonetheless as the climate warms in future, climate models which simulate these events suggest that similar disruptions will occur up to 3 times 
every 100 years for the more extreme of the standard climate change scenarios. This is consistent with a projected strengthening of the Brewer-Dobson circulation due to increasing stratospheric wave activity (14) and the recently observed weakening of the QBO amplitude in the lower stratosphere (21) under climate change. However, robustly modelling how the QBO, its underlying processes and external influences will change in the future, remains elusive.

There is a further outcome of the 2016 disruption of the QBO. Following an eastward QBO at the onset of the 2015/2016 winter, the QBO at the onset of the coming winter of 2016/17 was expected to be westward. The disruption of early 2016 means that an eastward QBO phase is now again expected in the lower stratosphere. Due to the expected QBO influence on the Atlantic jet stream, this increases the risk of a strong jet, winter storms and heavy rainfall over northern Europe in the coming winter $(22,23)$.

\section{References and Notes:}

1. R. A. Ebdon, Notes on the wind flow at $50 \mathrm{mb}$ in tropical and sub-tropical regions in January 1957 and January 1958. Q. J. R. Meteorol. Soc. 86, 540-542 (1960).

2. R. J. Reed, W. J. Campbell, L. A. Rasmussen, D. G. Rogers, Evidence of a downwardpropagating, annual wind reversal in the equatorial stratosphere. J. Geophys. Res. 66, 813$818(1961)$.

3. M. P. Baldwin et al., The quasi-biennial oscillation. Rev. Geophys. 39, 179-229 (2001).

4. J. M. Wallace, General circulation of the tropical lower stratosphere. Rev. Geophys. 11, 191 (1973).

5. P. H. Haynes, The latitudinal structure of the quasi-biennial oscillation. Q. J. R. Meteorol. Soc. 124, 2645-2670 (1998).

6. U. Niemeier et al., Initial fate of fine ash and sulfur from large volcanic eruptions. Atmos. Chem. Phys. 9, 9043-9057 (2009).

7. J. R. Holton, H.-C. Tan, The Influence of the Equatorial Quasi-Biennial Oscillation on the Global Circulation at $50 \mathrm{mb}$. J. Atmos. Sci. 37, 2200-2208 (1980).

8. J. A. Anstey, T. G. Shepherd, High-latitude influence of the quasi-biennial oscillation. $Q$. J. R. Meteorol. Soc. 140, 1-21 (2014).

9. J. Kidston et al., Stratospheric influence on tropospheric jet streams, storm tracks and surface weather. Nat. Geosci. 8, 433-440 (2015).

10. A. A. Scaife et al., Predictability of the quasi-biennial oscillation and its northern winter teleconnection on seasonal to decadal timescales. Geophys. Res. Lett. 41, 1752-1758 (2014).

11. B. Naujokat, An Update of the Observed Quasi-Biennial Oscillation of the Stratospheric Winds over the Tropics. J. Atmos. Sci. 43 (1986), pp. 1873-1877.

12. R. S. Lindzen, J. R. Holton, A Theory of the Quasi-Biennial Oscillation. J. Atmos. Sci. 25, 1095-1107 (1968).

13. J. R. Holton, R. S. Lindzen, An Updated Theory for the Quasi-Biennial Cycle of the Tropical Stratosphere. J. Atmos. Sci. 29, 1076-1080 (1972). 
14. N. Butchart, The Brewer-Dobson circulation. Rev. Geophys. 52, 157-184 (2014).

15. A. R. Plumb, R. C. Bell, A model of the quasi-biennial oscillation on an equatorial betaplane. Q. J. R. Meteorol. Soc. 108, 335-352 (1982).

16. R. E. Dickinson, Planetary Rossby Waves Propagating Vertically Through Weak Westerly Wind Wave Guides. J. Atmos. Sci. 25, 984-1002 (1968).

17. T. J. Dunkerton, Laterally propagating Rossby waves in the easterly acceleration phase of the quasi biennial oscillation. Atmosphere-Ocean. 21, 55-68 (1983).

18. K. Hamilton, A. Hertzog, F. Vial, G. Stenchikov, Longitudinal Variation of the Stratospheric Quasi-Biennial Oscillation. J. Atmos. Sci. 61, 383-402 (2004).

19. J. S. Kinnersley, S. Pawson, The Descent Rates of the Shear Zones of the Equatorial QBO. J. Atmos. Sci. 53, 1937-1949 (1996).

20. C. MacLachlan et al., Global Seasonal forecast system version 5 (GloSea5): a highresolution seasonal forecast system. Q. J. R. Meteorol. Soc. 141, 1072-1084 (2015).

21. Y. Kawatani, K. Hamilton, Weakened stratospheric quasibiennial oscillation driven by increased tropical mean upwelling. Nature. 497, 478-481 (2013).

22. R. A. Ebdon, The Quasi-Biennial Oscillation and its association with tropospheric circulation patterns. Aust. Meteorol. Mag. 104, 282-285 (1975).

23. C. Huntingford et al., Potential influences on the United Kingdom's floods of winter 2013/14. Nat. Clim. Chang. 4, 769-777 (2014).

24. D. P. Dee et al., The ERA-Interim reanalysis: configuration and performance of the data assimilation system. Q. J. R. Meteorol. Soc. 137, 553-597 (2011).

25. NCAS British Atmospheric Data Centre, European Centre for Medium-Range Weather Forecasts: ECMWF operational analysis: Assimilated Data (2006), (available at http://catalogue.ceda.ac.uk/uuid/c46248046f6ce34fc7660a36d9b10a71).

26. D. G. Andrews, M. E. McIntyre, Planetary Waves in Horizontal and Vertical Shear: The Generalized Eliassen-Palm Relation and the Mean Zonal Acceleration. J. Atmos. Sci. 33, 2031-2048 (1976).

27. E. P. Gerber et al., Assessing and Understanding the Impact of Stratospheric Dynamics and Variability on the Earth System. Bull. Am. Meteorol. Soc. 93, 845-859 (2012).

\section{Acknowledgments:}

We thank the European Centre for Medium-Range Weather Forecasts for providing ERAInterim and Operational Analysis data (www.ecmwf.int/en/forecasts) and the Freie Universität Berlin for providing radiosonde data (www.geo.fu-berlin.de/en/met/ag/strat/produkte/qbo). The CMIP5 data was obtained from the British Atmospheric Data Centre (browse.ceda.ac.uk/browse/badc/cmip5). A summary of data used in the study is listed in Table S1. SO was supported by UK NERC grants NE/M005828/1 and NE/P006779/1. AS, JK and NB were supported by the Joint UK BEIS/Defra Met Office Hadley Centre Climate Programme 
(GA01101). AS and JK were additionally supported by the EU FP7 SPECS project. We acknowledge the scientific guidance of the World Climate Research Programme for helping motivate this work, coordinated under the framework of the Stratosphere-troposphere Processes and their Role in Climate (SPARC) QBOi activity led by SO, JA, NB and KH.

Author contributions: The analysis of observations and reanalyses was performed by KH, CZ, SO, JA and NB. JK and AS provided the analysis of the seasonal forecasts and VS identified analogous events in global climate model output. AS first alerted us to the disruption of the QBO in observational data. All authors were equally involved in the interpretation of the results and preparation of the manuscript. 

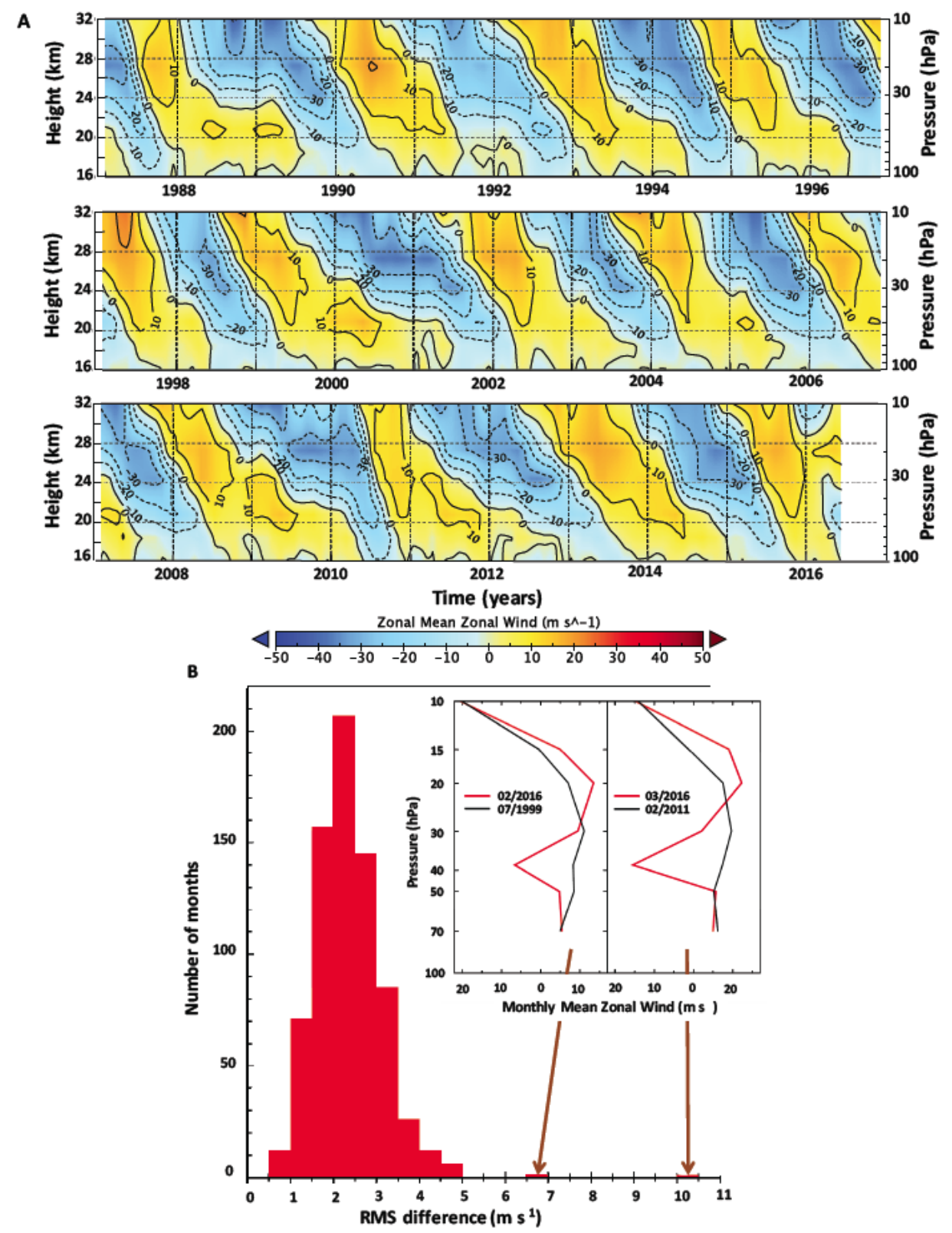

Fig. 1. Evolution of the $Q B O$ showing regular repeating wind structures and anomalous westward winds in 2016. (A) Vertical profile time series of monthly mean zonal mean eastward wind averaged over $5^{\circ} \mathrm{S}-5^{\circ} \mathrm{N}$ showing descending eastward (yellow) and westward (blue) wind regimes (24) for the last thirteen observed QBO cycles. (B) Histogram of root mean square (rms) differences in monthly-mean eastward wind averaged over the 70,50,40,30,20,15 and $10 \mathrm{hPa}$ levels between each of the 724 monthly profiles from all 27 observed QBO cycles and its closest match in the record (11). Only matches between profiles separated by more than six months were evaluated to ensure only matches from earlier or later $Q B O$ cycles were considered. The inset panels show monthly-mean profiles together with their best matches for February and March 2016. 

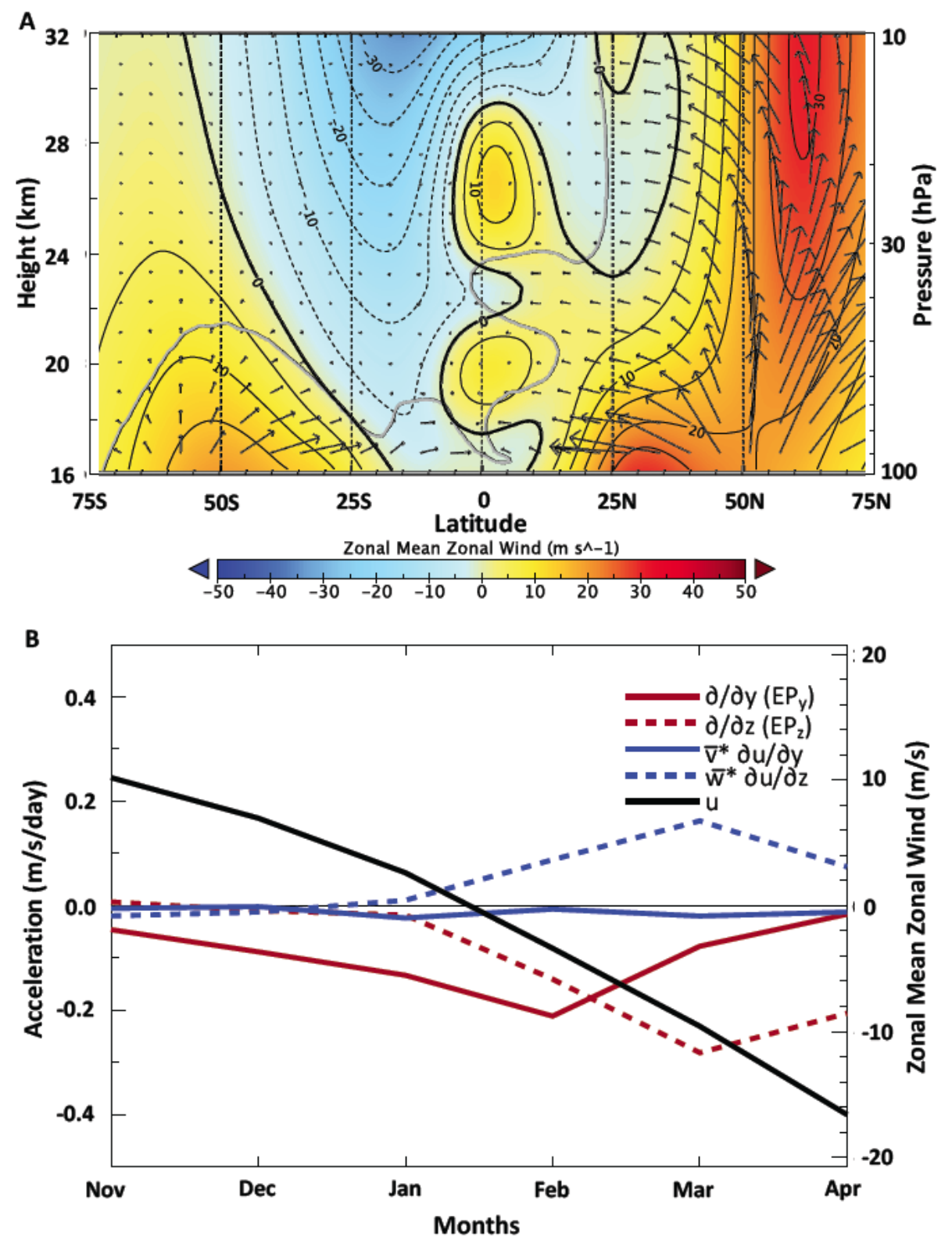

Fig. 2 Wave driven circulation changes associated with the formation of $40 \mathrm{hPa}$ westward $u$. (A) Latitude-pressure plot showing February 2016 mean zonal mean wind (filled and black contours), Eliassen-Palm (EP) flux (26) (black arrows) and their extent (grey contour). EP flux is indicative of wave propagation direction and shows wave activity leaving the troposphere near $50^{\circ} \mathrm{N}$ and entering the tropics near $40 \mathrm{hPa}$. (B) Monthly mean time series of horizontal (solid lines) and vertical (dotted) contributions of EP flux divergence (red) and u-advection (blue), averaged over $5^{\circ} \mathrm{S}-5^{\circ} \mathrm{N}$. Westward acceleration evident near 40hPa started in November 2015 and continued during January-February 2016. Monthly mean u time series (solid black lines) indicates development of easterly anomaly. Diagnostics derived from 6-hourly global operational analysis data $(24,25)$. 


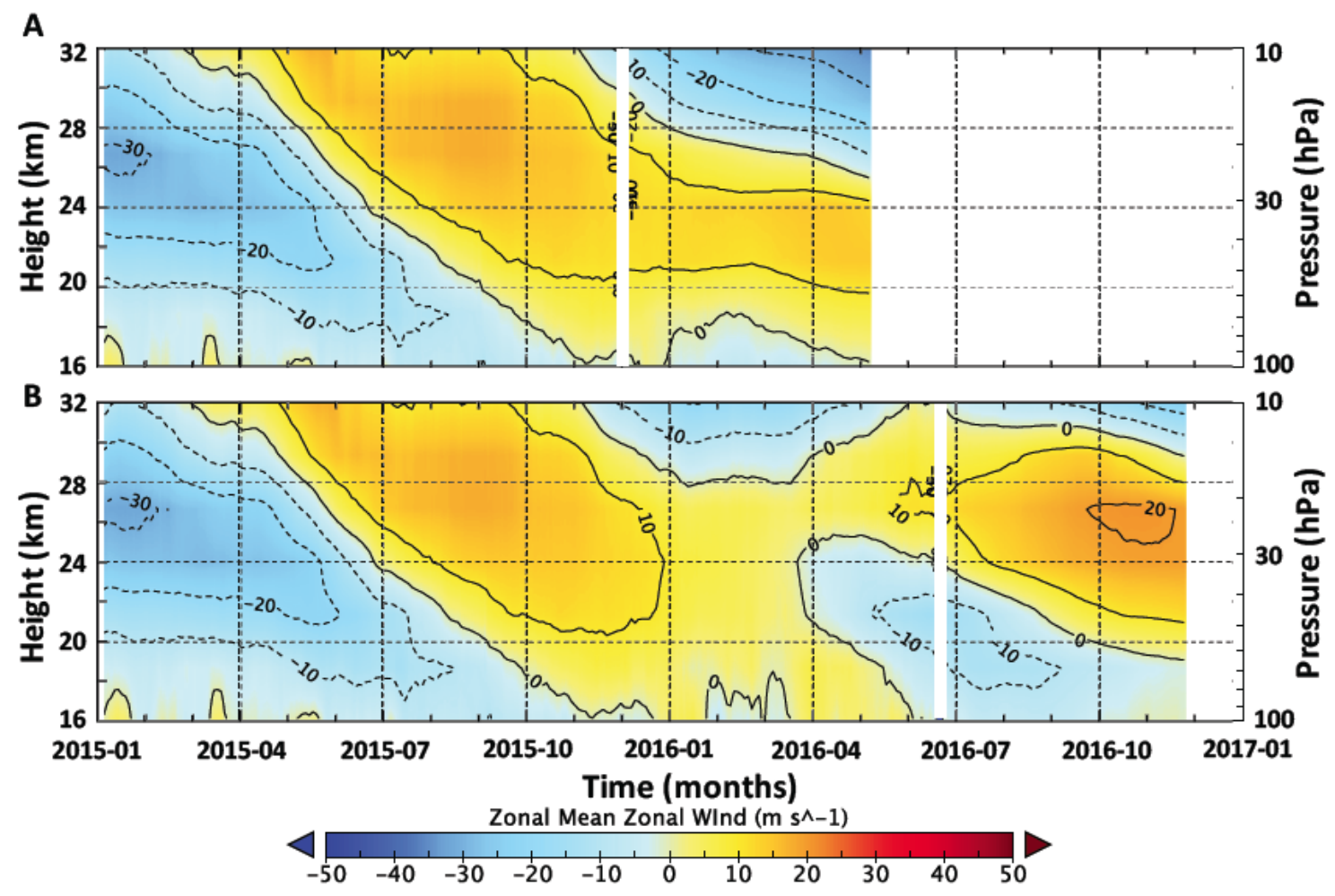

Fig. 3 Long range forecasts of the $Q B O$ from before and during the 2016 disruption.

Forecasts from 1st December (A) show the usual phase progression of descending eastward wind in the lower stratosphere. Forecasts from June (B) show growth, descent and decay of the anomalies westward wind near 50hPa and a second period of eastward QBO winds in late 2016. 


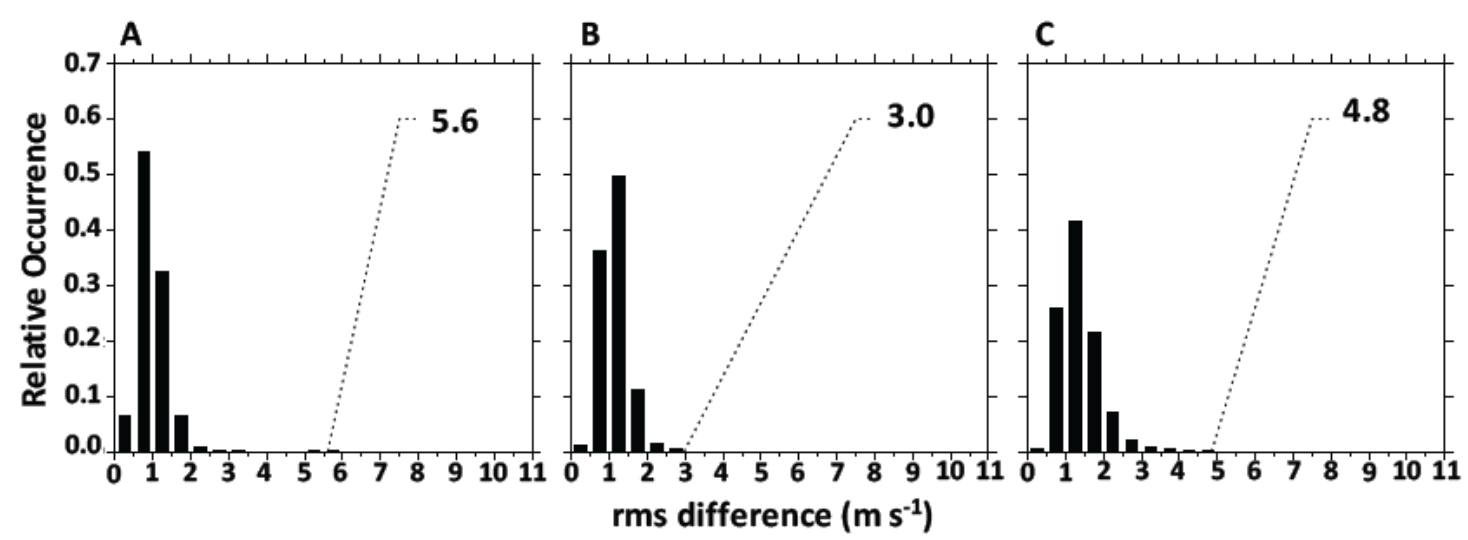

D

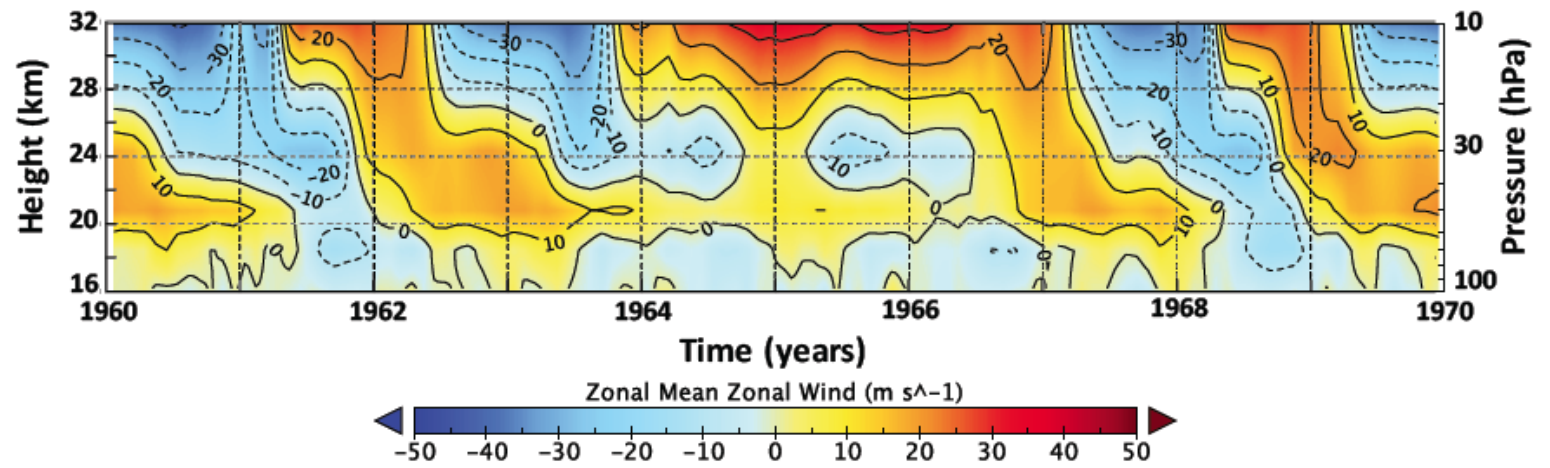

Fig. 4 Extreme QBO activity diagnosed in contributions to the Coupled Model

Intercomparison Project Phase 5. Best-match rms differences for (A) HadGEM2-CCS, (B) MIROC-ESM-CHEM and (C) MPI-ESM-MR (27). Although outliers occur in the three model simulations, only one model produced analogous westward jet formation seen in observations. (D) The formation of westward $u$ within a descending eastward jet is seen during 1964 in run rlilpl of MPI-ESM-MR. Anomalous westward $u$ is seen near 100hPa and strengthened 10hPa eastward $u$ last until 1967. Only one event occurred during the 145 year run. 